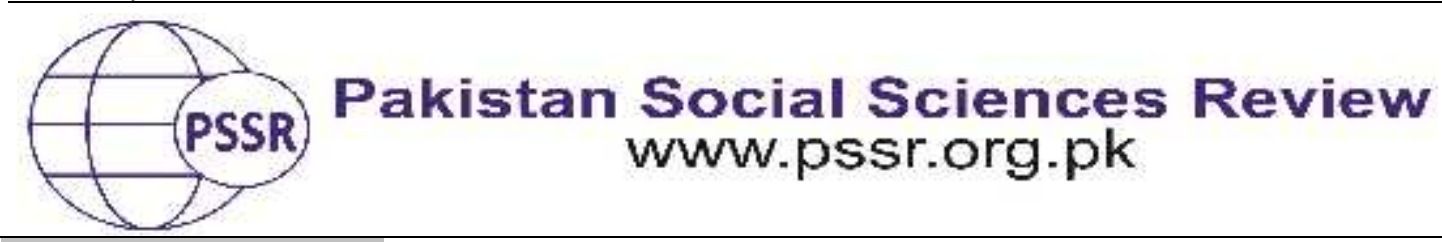

RESEARCH PAPER

\title{
Analysis of Pedagogic Concerns about Covid-19 in Educational Institutions in Pakistan
}

Prof. Dr. Muhammad Yousuf Sharjeel ${ }^{1}$ Mahmood Ahmed Dool 2

Syed Tanweer Ahmed Shah ${ }^{3}$

1. Professor, Department of Education, Faculty of Social Sciences and Education, SZABIST-Karachi, Sindh, Pakistan

2. Assistant Professor, Department of Education, Sukkar IBA University-Sukkar, Sindh, Pakistan

3. Lecturer. Department of Education, Sukkar IBA University-Sukkar, Sindh, Pakistan

\section{PAPER INFO}

Received:

July 29, 2020

Accepted:

September 05, 2020

Online:

September 30, 2020

Keywords:

Covid-19,

Impeding

Concerns,

Lockdown

Pedagogic

Concerns,

Social Distancing

Corresponding

Author

yousufsharjeel@

hotmail.com

\section{ABSTRACT}

The aim of this research is to inform the readers that Covid-19 pandemic has ceased all pedagogic and scholastic activities through the globe and Pakistan is no exception. This seizure has caused many individuals and organizations to halt their professional, personal and organizational schedules. Academic organizations have also suffered tremendously. Impeding concerns include payment of tuition fees, admission fees and other academic costs. The study analyzes some measures for the educational institutions in the light of Covid-19. This research suggests inviting alumni for counseling, psychological counseling and partnering with digital education platforms to provide high-quality courses. Educational institutions can use this opportunity to teach students about the pandemic, the challenges it presented, and the mental willpower needed to overcome this robust goblin-like viral attack. Business, social sciences and medical students could also benefit from lessons on how the market adapted and innovated when faced with the challenge of the lockdown. There will also be some attention directed to the problems faced by universities and their management and faculty. Finally, some recommendations are provided to address these matters. A lot of information can be gleaned from locally published scientific articles, some of which are still under review.

\section{Introduction}

There is some debate over the effectiveness of school closures on curbing the spread of an outbreak since there is no reliable data on the effectiveness of preventive measures independently.It has, however, been theorized that school closures on their own are not very effective against an outbreak, but are a useful 
measure when used alongside other measures like social distancing, lockdown, etc. (Ferguson, et al., 2020). There are also other measures that could have been taken; such as staggering school start and end times for different grades, that could have allowed schools to continue operating during these unprecedented times. However, there is no substantial and valid research on their safety and efficacy(Viner, et al., 2020). In the context of Pakistan, these questions are vital to answer, as the current pandemic and associated lockdown measures have exposed many deficiencies in the educational system, and caused an excessive level of stress for parents, students, and school staff. One study by Aga Khan University revealed that $75 \%$ of the adults in Pakistan are suffering from moderate to severe levels of stress, and around a third of those surveyed have abnormal levels of anxiety (The News International, 2020). There have been several efforts by the government and by school administrations to try and avert the educational crisis caused by the lockdown through the implementation of online learning systems. However, Pakistan simply lacks the digital literacy skills and infrastructure to make this project very successful (Economist Intelligence Unit, 2020).

\section{Literature Review}

The COVID-19 pandemic and lockdown have had a widespread impact on the education sector, with some experts predicting losses as high as $\$ 2$ billion (The Academia Magazine, 2020). In addition to the immediate losses, the fallout of this will reach far into the future as financial troubles could lead to many students dropping out from elementary and secondary school, which will lead to fewer admissions in higher education in the future. Even those who continue their education will be affected, as the prolonged period away from their studies would inevitably lead to losses in their retained knowledge. A study of the effect of school closures in Pakistan found that when schools affected by the 2015 earthquake closed down for 14 weeks, the children attending them suffered a loss in learning equaling to 1.5 to 2 years' worth of education; a deficit which remained even after 4 years had passed (Masood \& Qureshi, 2020). The researchers estimated that this could lead to a loss of $15 \%$ of their overall revenue in their adult lives if the deficit were not remediated (Andrabi, Daniels, \& Das, 2020). It is plainly evident that the current school closures, which have already crossed the 20 -week mark, will have even more disastrous repercussions. In addition, females, both student and teacher alike, are more likely to be affected by the school closures as patriarchal attitudes would lead to them having to take up a greater share of responsibility in the house. When schools eventually open, they will be faced with the daunting task of balancing their old responsibilities with their new ones. There is also a tendency, especially amongst the poor and less educated, to favor the education of boys over that of girls. This can be seen from the literacy rates in Pakistan, which stand at $52.4 \%$ of women against $72.5 \%$ of males. The lockdown and the associated financial difficulties could influence families to pull their girls out of school, which would further increase the educational divide even more over time (National Commission on the Status of Women, 2020). 
The school closures have also affected their teachers and staff. The schools have to continue paying their employees, even during the closure; but with families reluctant to pay school fees during the economic crisis of the lockdown, their only options are to either pay out of their own pockets, or let them go. This situation is especially true for those schools catering to lower-income people. In Pakistan, there are numerous low-cost private schools that employ over 900,000 teachers, many of whom are female. This makes the private education sector the chief employer of women in Pakistan (Masood \& Qureshi, 2020). The closure of many schools is catastrophic not only for the students, but also for these teachers. Even those schools which have managed to stay open have to struggle with the advent of e-learning systems, and many lower-end schools lack the infrastructure necessary to shift their teaching online, leaving them no option, but to shut their doors. The problems with e-learning lie on both ends of the spectrum; many students, especially in rural parts of the country, lack access to stable internet and electricity services, while teachers also have to contend with their inexperience with these systems. Pakistan at 76 out of 100 countries on the 'Inclusive Internet Index' and low levels of digital literacy and poor network quality are cited as major obstacles impeding progress (Economist Intelligence Unit, 2020).

Students in areas with poor internet connectivity often have to travel long distances or brave difficult climbs just to get a good enough signal (Zahra-Malik, 2020), and protests have also broken out in some parts of the country over the inequity of the e-learning and assessment systems (Ahmed, 2020).Meanwhile, teachers are left grappling with online systems without receiving any proper training on them leading to low-quality lessons. These issues have stymied the education of the nation's youth to such an extent that a petition was launched to stop sub-par lessons from being delivered until the issues were addressed (Hassaan, 2020), and the Higher Education Commission (HEC) of Pakistan had to step in and shut down online university classes that did not meet their quality standards (ProPakistani, 2020). However, with the sheer number of public and private schools in Pakistan, it would be currently impossible for the government to effectively regulate all of them. Some independent organizations have stepped up to address these issues (Centre for Economic Research in Pakistan (CERP), 2020), but it is obvious that a lot of work remains to be done, especially in addressing the lack of infrastructure on the students' end. In addition to addressing the infrastructure issues, there is also an urgent need to address the lack of digital literacy skills among teachers. Some teachers took the initiative to switch to e-learning when the schools were first closed down, but most waited for official instruction from the government or school leadership (Ahmed K. , 2020)(Khan, Niazi, \& Saif, 2020).

This is indicative of the fact that most teachers in Pakistan did not even consider the possibility and potential of e-learning. The complaints from the students also reveals that many do not know how to effectively switch from traditional pedagogy to online teaching. It is necessary that teachers have both the skills and the equipment needed to effectively teach online. While it would be difficult, if not 
impossible, for the schools or the government to provide these necessities, it would be easier if third-party philanthropic organizations were involved. It is imperative that teachers receive digital literacy training not just for now, but also as preparation for any potential similar future events.

The government of Pakistan has taken some steps to address the educational needs of school children; Since the COVID-19 pandemic hit Pakistan and forced schools to be shut down, the government launched a tele-school channel. The channel broadcasts one hour of content per grade for kids from preschool to high school every day. The medium of television was likely chosen as they are much more common across Pakistan than internet capable devices, $63 \%$ of the former against $36 \%$ of the latter. There are also issues with low internet access and poor digital literacy mentioned above that likely influenced this decision. The government is also looking into airing educational radio programming aimed at children, since many poor families in rural areas who cannot afford television services are likely to have at least a radio. While the tele-school is certainly a step in the right direction, it will take some time before its content can be perfected. The current program quality can be uneven at times, with some content that is too fast-paced, or focusing on subject matter that is far too complicated for its intended audience. It is encouraging to note that the Education Minister of Pakistan has acknowledged the issues, and is committed to improving the tele-school channel (George, 2020). In order to ensure that children benefit from this educational content of the tele-school, it is essential that they be engaged and interested by the programming. Nadia Naviwala believes that language and literacy should be strongly emphasized in the tele-school content, since these are area of concerns amongst Pakistan's youth. The content also needs to strike a balance between being fun while still retaining its primary function to ensure that the tele-school achieves its goal (Naviwala, 2020).

There are numerous problems with the currently-adopted school closures model in addition to the countless lost jobs resulting from schools closing down, and the consequences this spells for the education of our nation's youth. There is also the question of the safety measures that need to be adopted to prevent the spread of the virus amongst the student population when schools open up again. We can see from the examples of several schools in the USA the necessity of implementing safety measures when they open up; they had to shut down again when several students and staff got infected within a week of reopening. A recent study suggested that young children are less likely to spread the virus than older children (Park, et al., 2020). All of this points to an urgent need to carry out more research into both safety measures that should be adopted when schools reopen. These safety measures could then be utilized in the case of any future events to keep schools open.

\section{Material and Methods}

In the light of the ongoing pandemic, most of the researchon its long-lasting effects is still being carried out, and there is already a lack of attention given to psychological issues in Pakistan. Much of the statistical data currently available and 
discussed in this report is from college and university students and staff, since getting insights into the psychological well-being of younger children is a difficult task, especially with the prevalent attitudes about psychology in Pakistan.There is also a discussion on the practical issues that students and staff face with the online learning systems being implemented. This information is mostly qualitative in nature, and is drawn from news articles and interviews. All of this information is used to derive the current psychological state and morbidities faced by the academic population of Pakistan, as well as the issues that are likely to crop up in the longterm. Several recommendations are then provided to mitigate and avert these consequences. A critical survey analysis was performed using online applications and personal visits to as many individuals and organizations as possible. A sample of $n=127$ respondents recoded their responses on voluntary basis. A sub-sample of 26 parents and heads of schools and colleges was also obtained in the study.

To carry out the study, the notice, emails and calls were made to 274 individuals and educational organizations operating on the suburban city of Karachi and Hyderabad. Upon receiving consent from these 274 individuals and organizations, the rate of response was 127 only owing to various internets, manual and other issues. Some female participants refused later on as they felt that their interviews would cause them personal inconvenience. Received responses were analyzed in the light of statements posed in the questionnaire.

\section{Psychological Issues and Challenges}

School closures have been found to be effective in reducing peak infection rates of influenza by up to $29.7 \%$ (Nafisah, Alamery, Nafesa, Aleid, \& Brazanji, 2018), but not cumulative rates. This is likely due to the fact that even though children are not going to school, they do not stay confined to their houses and instead maintain social contact with their friends at other locations. Additionally, school closures are most effective when the virus has a reproduction number (a measure of the number of new infections that a single infected individual can cause in a susceptible population) below 2 (Jackson, Mangtani, \& Vynnycky, 2014). Interestingly, COVID19 has been found to have a reproduction number of between 2.2- 6.5, depending on the country, outbreak stage, etc. (Thomas, 2020). In Pakistan, this number is currently estimated to be around 1 (EpiForecasts, 2020). Another online study of 1,134 students from four different universities in Lahore also assessed their anxiety and depression levels through the use of the GAD-7 and PHQ-9 surveys, as well as their sources of distress and coping mechanisms. The results revealed that $34 \%$ of the participants had moderate to severe levels of anxiety, and $45 \%$ had similar levels of depression. Interestingly, those respondents over 31 years of age were found to have significantly lower levels of depression compared to their younger counterparts. Meanwhile, those participants who had a friend, relative, or acquaintance infected with the virus showed significantly higher levels of anxiety.

This seems to match with the results of the sources of distress survey, which revealed that the vast majority $(70.9 \%)$ feared for the lives and safety of their friends 
and family, compared to fearing for themselves (41\%). This also mirrors the results of the Aga Khan University study mentioned earlier, wherein the percentage of people fearing for their loved ones and fearing for themselves was $76 \%$ and $36 \%$ respectively. With regards to coping mechanisms employed by the surveyed students, the results were aggregated using the Brief-COPE questionnaire, which categorizes responses into 14 potential coping methods. Of particular interest in these methods are: religion, self-blame, acceptance, and substance use. The study found that the most common coping strategy used by the surveyed Pakistani students was religious coping, followed by acceptance, and substance abuse was the lowest. However, males generally tended to rely on these less than females, who were in turn, less reliant on humor and planning than males (Salman, et al., in press).

Ultimately, these students would end up falling behind in their studies, compared to their more well-off peers, when universities are eventually allowed to re-open. Thus, they would lack the motivation to even continue their studies, which would lead to high dropout rates.In the war against this disease, the soldiers on the frontline are undoubtedly the doctors, nurses, and other healthcare professionals. Therefore, it is vital that we understand not only the psychological needs and challenges facing them, but also those facing medical students, as they need to be prepared to risk their lives in this and any other future pandemic situations. An online study of 530 medical students found that $44.2 \%$ of them reported feeling emotional detachment from friends and family. Comparing anxiety and depression, only about a quarter of the students reported feeling depressed (23.6\%), but more students reported feeling anxious (38.9\%). This result matches the earlier mentioned studies, as this particular survey was carried out only about two weeks into quarantine.

As discussed earlier, the rates of depression at that time were low, compared to anxiety. It should be noted that most male respondents reported not feeling anxious $(50.9 \%)$, compared to those that did $(33.5 \%)$, but the values were almost the same with the females $(\approx 40 \%)$. Also, compared to students who were worried about getting infected themselves $(26.6 \%)$, many more were concerned about passing on the infection to their family $(37.7 \%)$. The survey also aimed to get the medical students' opinions about their ability to learn effectively during the lockdown period, and found that $50.6 \%$ of them agreed that their studying and work performance had deteriorated, and $43 \%$ of them had difficulty concentrating during their studies. However, most of the medical students did not have trouble remembering their subject contents nor with recalling old and new information.

All of this points to the fact that medical students are not only under a high amount of stress, but they are facing difficulty in continuing their studies as well. Another survey of medical students from a university in Lahore found that many students (56\%) were concerned about their family getting infected, echoing the results of several of the previously mentioned studies. Interestingly, this survey also asked about the respondents' confidence in the government's ability to handle the pandemic, and $79.2 \%$ of the response was negative. If there is a deficit of trust 
between healthcare professionals, both present and future, and the government, it would not only add to the stress of both the stakeholders, as well as the common public, but could potentially impair them from effectively combatting this disease.

Therefore, the importance of restoring trust and cooperation between the government and medical workers cannot be overstated. According to one of the results of the 'THE Leaders Survey' by Times Higher Education, which questioned 200 university leaders from across 53 countries, the hardest disciplines to transition successfully to an e-learning format were Medicine and Dentistry (25\%), followed by Biological Sciences (13\%) and Veterinary Sciences (12\%) (Times Higher Education, 2020). As such, extra care needs to be taken to ensure that the education of our future medical professionals is not compromised in the wake of this pandemic.

Not only children, but their parents would also be under an incredible amount of duress. It is not difficult to imagine the stress that parents would face due to the threat of the pandemic coupled with the economic decline brought about by the lockdown. On top of that, they would now have to deal with children who are stuck at home with them, and who would need a space wherein they could carry out their e-learning. For larger families, this may prove to be difficult to provide. Also, many higher education students who were in boarding would now be coming back home, potentially to conditions of poverty and inadequate access to the technology required for e-learning, and to a culture where their education may not be appreciated. Additionally, many of these children may be expected to help out with work around the house, especially for females, or with agriculture or business. These issues will undoubtedly add to the stress and frustration of both the parents and their children. There is also the fact that the parents will now have extra mouths to feed, and many things that they could have easily done, like cleaning, relaxing, etc. while their children were off at university or school would be difficult to accomplish now.

A study of American adults found that having school going children stuck at home due to the lockdown led to a decrease in certain intimate behaviors. The study attributed this to the parents having to juggle multiple roles as both caregiver and educator, leaving them little time, space or energy to engage in intimate acts with their partners (Hensel, Rosenberg, Luetke, Fu, \& Herbenick, in press). It would not be surprising if there were a similar situation in Pakistan, even when considering older children.

Apart from the availability, the other major issue that students have to contend with is the low quality of the lessons being provided. Most instructors lack adequate training to conduct lectures online. Issues range from being unaware of how to use the equipment provided, how to help students solve any technical issues they may face, and a lack of coordination between instructors leading to classes often being scheduled at the same time. When looking at the effect that school closures have had in the current COVID-19 outbreak and the past SARS and MERS outbreaks, the data is fairly inconclusive. Additionally, the students are also 
inundated by information shared on social media sites, much of which may be fake. There is no shortage of rumors and misinformation spreading during these stressful times, even in Pakistan. This would undoubtedly add to the stress and confusion of the populace, as they become unsure of who they can trust.While the overall preventative measures comprising quarantine, social distancing, school closures, etc. are certainly useful in reducing the spread of the infection, the relative contribution of each is not discussed. Some modelling studies found that school closures are ineffective on their own compared to other measures, and a combination of preventive measures was the most effective (Ferguson, et al., 2020). There is no data on the economic impact of school closures, or alternative measures like social distancing in classes or staggering school start and break times across different classes and years (Viner, et al., 2020). Although the closure of academic institutions may not be as effective as one would hope, it is a double-edged sword from a psychological standpoint for parents and students; while there would be an initial burst of elation at the prospect of an extended vacation, the reality and dangers of the pandemic, as well as the extended disruption in daily routine would inevitably lead to an increase in anxiety, and possibly even depression.

\section{Impact on Households and Institutions}

In addition to those from poor households, women were also unduly affected by the lockdown, as they bear the brunt of small-minded cultural expectations. They are expected to aid with the housework, and are at greater risk of physical and sexual violence. This could lead to fewer girls returning to their studies when schools re-open, and a greater gender divide in higher education over time. Out of all the academic disciplines, the most severely affected by the shutdown are those related to medicine and health, as many practical concepts are difficult to teach and test for with e-learning. Finally, the families of these students are not only burdened by the economic hardships brought about by the closure of businesses, but are also burdened with providing the resources that the students in their family need to continue their studies.

\section{Teaching and Learning Scenario}

If students are suffering in their studies, then so too are the universities and professors tasked with instructing them. Their primary challenge comes from the difficulty of justifying the high fees being charged in spite of the blighted university experience. Many students have taken to demanding refunds or partial discounts as a result. There is also the issue of assessing the students' capabilities, both for the progression of current students and the enrollment of prospective ones. With the former, many board exams have been cancelled, forcing universities to amend their admissions criteria; while for the latter, it is difficult to ensure fair testing with online examinations, not to mention those who are excluded due to a lack of the necessary technology.In the long term, this would eventually mean fewer women in higher education as well. 
Furthermore, those students who lived with an abusive household member and got some reprieve and hope through their education and going to school and university; as a result of the lockdown and increasing rates of unemployment, they would face an increased risk of violence. In Pakistan, $28 \%$ of women between the ages of 15-49 have experienced physical violence, and 34\% of married women have experienced some form of spousal abuse. The lockdown would inevitably force the abuser and the victim in such households to be together for longer periods of time, and unemployment would add to the stress, depression, and anxiety of the abuser, thereby increasing the risk of violence and sexual exploitation of women and children (National Commission on the Status of Women, 2020).

In conclusion, students of higher educational institutes across Pakistan are facing anxiety, depression, and emotional detachment. While the levels of anxiety seemed to be higher earlier during the lockdown, they eventually dropped as depression rose over time. This was likely due to the students eventually adapting to their new routines during the lockdown, as well as the constant exposure to news and media about the virus. Most students were concerned more for the well-being of their families, rather than themselves. Of particular note are female students and medical students, as the former are at risk of dropping out or being exposed to violence, while the latter are facing more difficulties in continuing their studies through e-learning. These two groups, especially the former, as a result suffer far more anxiety and depression than their peers. Speaking of e-learning systems, while they can allow students across the nation to continue their studies, their implementation is rife with problems. For starters, the infrastructure necessary to support them is simply not there, with many students being deprived of the opportunity to learn simply because they cannot get proper internet, or lack the money or skill needed to use an appropriate computer or mobile system. Additionally, the instructors who are supposed to be teaching through e-learning systems often lack the training necessary to use the system and help their students use it as well.

Finally, just as students are experiencing stresses, so too are their parents, since they also have to potentially contend with unemployment on top of the pandemic and being stuck with their children. The expectations of parents can play a key role in adding to the frustrations that both the child and the parent experience. It should be noted that the above-mentioned surveys were carried in-person and online, and therefore, naturally exclude those segments of the student population that are suffering from a lack of access to the internet. If their responses were to be included, it is likely that the rates of psychological morbidities would be higher.

One method around this issue is to require students to take examinations whilst observing them through their webcams, though this inevitably raises privacy concerns and also requires the students to have a computer setup with a webcam, which would be difficult for those Pakistani students who are already hard-pressed to afford a decent computer system. Other methods being touted include viva voce 
examinations and continuous assessment with short assignments and projects (Times Higher Education, 2020). Of course, it is impossible for a one-size-fits-all approach, as the appropriate assessment methodology would depend on the topic being tested and the resources available to both the instructor and the students. Medical topics are perhaps the hardest to grade, as all these methods can test the theoretical knowledge of the students, but examinations like the Task Oriented Assessment of Clinical Skills (TOACS) are not easily possible in the current climate.

While student admission rates and procedures are certainly of concern, a more alarming issue has quickly arisen in the crucible of the pandemic and the rise of e-learning; the fees being charged by the universities. It is undeniable that attending a higher education program at a university is not just about the tuition, but also about the university experience. This encompasses not just the studies, but also the networking with colleagues, professors and employers, the experience of independence for many, especially for those who chose to board, the unique environment of the campus, the clubs, etc. However, due to the closure of universities, the students are deprived of this experience. As such, many argue that they should not have to pay exorbitant fees, especially with the economic crisis that the lockdown has resulted in. There are calls from students and their parents, both in Pakistan and abroad, to have the university's tuition fees reduced in the current and coming terms since they are paying for a sub-par online-only learning experience. Conversely, the universities have not responded positively to these calls. Although some universities have refunded room and board fees, most have neither refunded nor discounted tuition fees (Anderson, Feeling Shortchanged, 2020).

\section{Summary}

To recap, both universities and staff have been adversely affected as a result of the pandemic. For universities and instructors alike, the biggest challenge they face is that of successfully transitioning their courses online. This is particularly difficult as both parties, as well as the students they teach face a lack of both experience and resources, and certain types of training, such as internships, are not easily possible. Following this is the challenge of recruiting students for the coming term. With board exams cancelled, universities have to decide on new recruitment criteria that maintains the rigor, timeliness, and fairness of past admissions requirements. They also have to contend with reduced applications overall, as many students will chose to defer their studies until the lockdown is over, international travel is possible, and their finances have recovered. This will undoubtedly have an impact on the finances of the university, and by extension, on the grants, scholarships, and salaries they can offer. Meanwhile, current students at many universities are protesting the high tuition fees being charged, since they have been deprived of the university experience and online classes are no substitute. Some institutions have offered partial refunds or discounts, but most are refusing to budge, creating a rift between them and their students.

\section{Conclusion}


In conclusion, we should learn from the example of Singapore on how to adapt after a viral outbreak, specifically in ensuring that academic staff are trained to be able to make, store, and transfer their lessons to an online format, and that this event is not quickly wiped from the public's collective consciousness. We should also have a framework in place to allow for the quick production and dissemination of pertinent facts about a pandemic or other similar incident to students, staff, and the common public. There should also be official rules that staff can follow in the case of a similar incident. With regards to addressing the lack of resources amongst students to fully avail themselves of online learning, the authors propose the construction of buildings that can serve a similar function to internet cafes in remote villages and impoverished areas. In conclusion, we should learn from the example of Singapore on how to adapt after a viral outbreak, specifically in ensuring that academic staff are trained to be able to make, store, and transfer their lessons to an online format, and that this event is not quickly wiped from the public's collective consciousness. We should also have a framework in place to allow for the quick production and dissemination of pertinent facts about a pandemic or other similar incident to students, staff, and the common public. There should also be official rules that staff can follow in the case of a similar incident. With regards to addressing the lack of resources amongst students to fully avail themselves of online learning, the authors propose the construction of buildings that can serve a similar function to internet cafes in remote villages and impoverished areas.

\section{Recommendations}

Although there is much work to be done in order to counter the issues described above, we have the benefit of being able to learn effective strategies from others around the world. This pandemic is indisputably a historic moment that will change the world in countless ways. Higher education must also be able to adapt to this new world, and that requires that students, institutions, private companies and government bodies set aside their differences and come together for the greater good. In Pakistan, this means that we cannot just implement half-baked ideas that may work now, but will become a burden in the future. We must carefully and strategically implement equitable plans that will maximize the utility of our available resources and increase them if and when possible.

Many villages and rural areas in Pakistan lack access to internet and stable electricity, especially in KPK and Balochistan. With providing laptops to each household with university students, provisions also have to be made to ensure that these premises have access to electricity and the internet, which would be difficult due to mountainous terrain, and there is the risk of the laptops being sold, damaged, or stolen. Instead, a single building could be built in each village that would include multiple computer systems. The capacity of the building would be dependent on the number of people living in that area. In this way, electricity and internet access only have to be ensured for these particular buildings, rather than the entire village. 
The construction of these "cafes" should be left to the army, as this would sidestep any potential instances of corruption and favoritism, and the expectation would be completed quickly and efficiently. The seating in these places should be segregated by gender to avoid any issues with conservative households. Their security and maintenance should also be left to the army, though they could hire people from the village to carry out menial work. The sites visited can be monitored to avoid any illegal activity. Students from schools and universities can be allotted fixed time-slots, during which they can access their lessons and work on their assignments. It would be ideal if instructors allow students to view recorded lessons instead of making attendance to live classes compulsory, as this would allow students with other household commitments to access the lessons at their own convenience. The funding and equipment for this endeavor can be provided by a coalition of universities working in tandem with the government and internet service providers. Finally, this would be beneficial in the long-term as well, as these centers can be utilized as adult education centers to teach the people in the village basic reading, writing, and digital literacy skills. They could even hire graduates from their own villages to teach at their respective centers.

Another step that universities can take is to call on their skilled alumni to aid in delivering courses. Alumni are a valuable resource that many universities neglect. Due to the lockdown, many of them may be struggling financially. The universities could offer them some small amount of money and training, in exchange for recording their particular understanding of difficult topics. Since many of them would be officially employed, they could bring their specific method of understanding difficult topics, as well as insights from their work to current students. For example, an engineer working with HVAC systems could explain how the topics they studied are applied practically in the field, or an accounting major could explain the method they used to make sense of a difficult concept. If done properly, this would aid the alumni by getting them some financial assistance, and the university would benefit by being able to boast about their talented alumni. 


\section{References}

Ahmed, K. (2020, March 06). Professor turns to online lectures as Sindh closes universities over coronavirus. Arab News - Pakistan: https://arab.news/6z4zu

Ahmed, R. U. (2020, June 29). Students arrested for demanding internet facilities in Balochistan. Advox: https://globalvoices.org/2020/06/29/students-arrested-fordemanding-internet-facilities-in-balochistan

Anderson, G. (2020, April 13). Feeling Shortchanged. Retrieved July 16, 2020, from Inside Higher Ed: https://www.insidehighered.com/news/2020/04/13/students-say-onlineclasses-arent-what-they-paid

Andrabi, T., Daniels, B., \& Das, J. (2020). Human Capital Accumulation and Disasters: Evidence from the Pakistan Earthquake of 2005. Oxford: Blavatnik School of Government, University of Oxford. doi:10.35489/BSG-RISE-WP_2020/039

Centre for Economic Research in Pakistan (CERP). (2020, April 16). Digital Education Response to Covid-19 in Pakistan. Centre for Economic Research in Pakistan (CERP): https://www.cerp.org.pk/pages/digital-education-response-to-covid19-in-pakistan

Economist Intelligence Unit. (2020). The Inclusive Internet Index 2020. https://theinclusiveinternet.eiu.com/explore/countries/PK/

Ferguson, N. M., Laydon, D., Nedjati-Gilani, G., Imai, N., Ainslie, K., Baguelin, M., . . . Ghani, A. C. (2020). Report 9 - Impact of non-pharmaceutical interventions (NPIs) to reduce COVID-19 mortality and healthcare demand. London: Imperial College.

George, S. (2020, May 19). In the world's fifth most-populous country, distance learning is a single television channel. The Washington Post. https://www.washingtonpost.com/world/asia_pacific/pakistan-coronaviruseducation-teleschool/2020/05/18/9ee159a8-8eee-11ea-9322-

a29e75effc93_story.html

Hassaan, M. (2020, March). Suspend the Online Classes and Refund the Fees (Pakistani Universities). https://www.change.org/p/higher-education-commission-hecpakistan-suspend-the-online-classes-and-refund-the-fees-pakistani-universities

Hensel, D. J., Rosenberg, M., Luetke, M., Fu, T.-c., \& Herbenick, D. (in press). Changes in Solo and Partnered Sexual Behaviors during the COVID-19 Pandemic: Findings from a U.S. Probability Survey. medRxiv. doi:10.1101/2020.06.09.20125609 
Khan, A. A., Niazi, S., \& Saif, S. K. (2020, March 26). Universities unprepared for switch to remote learning. University World News: https:/ / www.universityworldnews.com/ post.php?story=20200326141547229

Masood, S., \& Qureshi, Z. (2020, May 16). The Analytical Angle: Covid-19 and the looming education crisis. Dawn.com: https:/ / www.dawn.com/news/1556855/the-analytical-angle-covid-19-and-thelooming-education-crisis

Nafisah, S. B., Alamery, A. H., Nafesa, A. A., Aleid, B., \& Brazanji, N. A. (2018). School closure during novel influenza: A systematic review. Journal of Infection and Public Health, 11(5), 657-661. doi:10.1016/j.jiph.2018.01.003

National Commission on the Status of Women. (2020). Gendered Impact and Implications of COVID-19 in Pakistan. Government of Pakistan, Ministry of Human Rights . Ministry of Human Rights. http://www.mohr.gov.pk/SiteImage/Misc/files/GenderedImpact.pdf

Naviwala, N. (2020, April 23). How 'Teleschool' Can Revolutionize Pakistan's Education System. Retrieved August 28, 2020, from United States Institute of Peace: https://www.usip.org/blog/2020/04/how-teleschool-can-revolutionizepakistans-education-system

Park, Y. J., Choe, Y. J., Park, O., Park, S. Y., Kim, Y.-M., Kim, J., . . Jeong, E. (2020, July 16). Contact Tracing during Coronavirus Disease Outbreak, South Korea, 2020. Emerging infectious diseases, 26(10). doi:10.3201/eid2610.201315

ProPakistani. (2020, April 01). HEC to Inspect the Quality of Online University Classes. Pro Pakistani: https://propakistani.pk/2020/04/01/hec-to-inspect-the-qualityof-online-university-classes /

Salman, M., Asif, N., Mustafa, Z. U., Khan, T. M., Shehzadi, N., Hussain, K., . . . Khan, M. T. (in press). Psychological Impact of COVID-19 on Pakistani University Students and How They Are Coping. medRxiv. doi:10.1101/2020.05.21.20108647

The Academia Magazine. (2020, June 05). COVID-19: Pakistan's Education Sector Faces $\$ 2 b$ In Losses. The Academia Magazine: https://academiamag.com/pakistanseducation-sector-faces-2b-in-losses/

The News International. (2020, July 14). Study suggest 75\% Pakistani adults suffering from stress during COVID-19 pandemic. The News International. https://www.thenews.com.pk/latest/686635-study-suggest-75-pakistani-adultssuffering-from-stress-during-covid-19-pandemic

Times Higher Education. (2020). THE Leaders Survey: Will Covid-19 leave universities in intensive care. Times Higher Education: 
https://www.timeshighereducation.com/features/leaders-survey-will-covid19-leave-universities-intensive-care

Viner, R. M., Russell, S. J., Croker, H., Packer, J., Ward, J., Stansfield, C., . . Booy, R. (2020, May 01). School closure and management practices during coronavirus outbreaks including COVID-19: a rapid systematic review. The Lancet Child $\mathcal{E}$ Adolescent Health, 4(5), 397-404. doi:10.1016/S2352-4642(20)30095-X

Zahra-Malik, M. (2020, July 14). The coronavirus effect on Pakistan's digital divide. BBC: https://www.bbc.com/worklife/article/20200713-the-coronavirus-effect-onpakistans-digital-divide 